\title{
Using Remote Sensing in Monitoring the Urban Green Spaces: A Case Study in Qorveh, Iran
}

\author{
Aynaz Lotfata
}

\section{ABSTRACT}

Urban green spaces are important to the physical activity, mental wellbeing, and health of urban residents. In medium-sized cities in Iran, urban green spaces have been ignored during the past decades. In this study, remote sensing and geographic information system was used to investigate the green space distribution in the built-up areas. Accordingly, normalized difference vegetation index (NDVI) and normalized difference built-up index (NDBI) were used to estimate urban green spaces distribution within the urban landscapes to measure the urban land use effect. The geospatial analysis results presented a lack of green spaces in built-up areas. Also, $16.8 \%$ of the total area of Qorveh city is considered as a dysfunctional urban fabric that $39.4 \%$ of the city's population live in this area. This study highlighted the usage of green space index with geospatial analyses in illustrating the urban green spaces' importance for planning. For the future urban land development scenarios, this approach could be used linking with regional planning approaches.

Published Online: January 25, 2021

ISSN: $2684-446 \mathrm{X}$

DOI : 10.24018/ejgeo.2021.2.1.102

Aynaz Lotfata*

Chicago State University, Chicago, IL, USA.

(e-mail: alotfata@gmail.com)

Keywords: Green space, Medium-sized cities, NDVI.

\section{INTRODUCTION}

Urban green spaces have been associated with health benefits and results comprising improved physical activity and social relations [1]. Urban green spaces refer to areas such as gardens, parks, greenways, and other areas with grass, trees, and shrubs [2], [3]. Urban green spaces improve the air quality, supply rich biodiversity to urban areas, restore groundwater recharge rate, and balance the surface land temperature [4]. Additionally, improved and abundant green spaces promote mental and physical health and reduce disease and mortality in urban residents by delivering psychological relaxation and stress alleviation, encouraging social cohesion, supporting physical activity, and decreasing exposure to air pollutants, noise, and excessive heat with a suitable urban green space planning and management [5]. In 2014, 54 percent of the world's population lives in urban regions, a proportion that is estimated to raise to 66 percent by 2050. Medium-sized cities are growing rapidly as people escape the overcrowded and increasingly expensive major metropolitan areas to small metro areas and small service centers [6]. Urban high-density in and around developing countries' medium-sized cities affects multiple aspects of the urban environment including lack of urban green space. While high-dense developments are widely maintained to make an important influence to accomplishing sustainable growth of cities in developed countries [7]. It is, hence, necessary to ensure that urban green spaces are easily accessible for all people and distributed fairly within the city [8], [9].

In addition to green space benefits on health, green spaces can drop surface runoff, energy depletion, increase carbon storage, and improve water quality [10]. Urban green spaces benefits have been highlighted in the metropolitan cities and bulky cities have sprouted urban greening agendas comprising the planting of more trees, growing the quantity of urban parks, and increasing the urban green roofs [11]. While urban greening programs have not been accentuated, are not spreaded equally and formally within the mediumsized cities in developing countries [12]. The principal reason for this inadequate and unequal arrangement comprises the dissimilarities in ideas of recreational landscape planning [13] and medium-sized cities have rapidly expanded both in population and built-up areas may cause fragmented green areas [14]. In developing countries, the urban landscape grows inwards and outwards as a consequence of dysfunctional, inefficient land uses and agricultural lands' conversions to built-up areas [15], [16]. Therefore, mediumsized cities in developing countries face multiple challenges including landscape fragmentation, conversion of lowly dense and dysfunctional areas into the highly dense built-up patches, and conversion of open spaces into the built-up patches [17], [18].

The lack of green areas in urban neighborhoods poses short- and long-term results linked with environmental changes and socioeconomic decline [19]. The lack of green areas accelerates the spatial and socioeconomic decline in the dysfunctional urban landscape as making green spaces are considered a challenge, predominantly in developing countries, in which there is pressure for space, assets, and development [20]. From this perspective, urban green spaces are urban areas in proximity to built-up areas [21].

There is a gap in the literature examining the spatial analysis of green spaces in the city of Qorveh, Iran. Thus, this 
study aims to use remote sensing (RS) and geographic information system (GIS) technology to analyze spatial arrangements of green spaces in Qorveh, Iran. This is the first potential research that examined the spatial arrangement of urban green spaces in this medium-sized city. The population of the city is assessed at 78,276 and $7 \mathrm{~m}^{2}$ green space per person. More importantly, due to its geographical location, it accommodates immigrants from surrounding large cities. It contributes to reducing population pressure on these cities. The role of medium-sized cities in Iran is becoming more important to balance regional population distribution. As a consequence, it is significant to assess the impacts of increasing urban built-up areas on urban green spaces in the study area. To achieve the purpose of this study, the green space index, which is based on basic types of green space cover and related characteristics, is used. The index can be extracted from remote sensing images to measure the spatial arrangement and distribution of green spaces in the urban city center and surrounding landscapes.

\section{METHODS AND MATERIALS}

\section{A. Study Area}

Qorveh city is located in Kurdestan province in western Iran between $34^{\circ} 44^{\prime}$ and $36^{\circ} 30^{\prime}$ north latitude and $45^{\circ} 31^{\prime}$ and $48^{\circ} 16^{\prime}$ east longitude. Around 2 percent of the Iranian population resides in Kurdestan province. Neighboring large cities are the city of Sanandaj to the north, Hamedan to the south, Zanjan to the east, and Kermanshah to the west (Fig. 1). The landscape of the city is lowland and flat with a mountainous and agricultural surrounding landscape. The height of the city is $1906 \mathrm{~m}$. The summer is hot and arid, while it is cold and dry in the winter. Over the year, the temperature typically varies from $-6.1{ }^{\circ} \mathrm{C}$ to $33.3^{\circ} \mathrm{C}$. The flora of Qorveh contains various plant species, including shrubs $(62 \%)$ and sparse vegetation (23\%) within 2 miles of Qorveh, shrubs (52\%) and sparse vegetation $(21 \%)$ within 10 miles of Qorveh and shrubs (49\%) and cropland (21\%) within 20 miles of Qorveh [23].

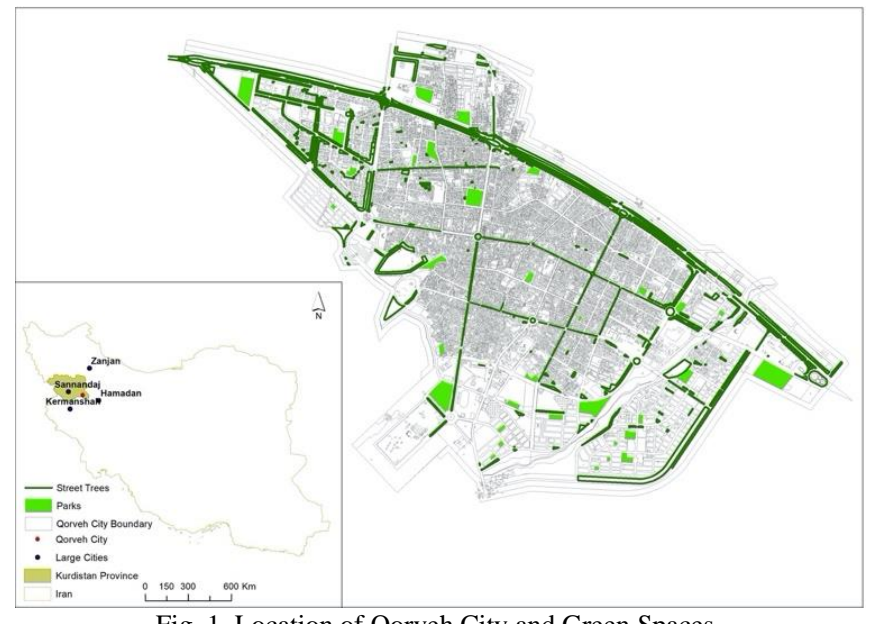

Fig. 1. Location of Qorveh City and Green Spaces.

\section{B. Geographic Analysis}

Vegetation indices are quantified from the multispectral data. One of the most regularly used green space indices is the normalized difference vegetation index (NDVI). NDVI is formulated as follows:

$$
\mathrm{NDVI}=(\mathrm{NIR}-\mathrm{R}) /(\mathrm{NIR}+\mathrm{R})
$$

where NIR (Band 8) characterizes near-infrared reflectance and $\mathrm{R}$ (Band 3) explains visible red reflectance. NDVI analysis can supply increased green space dynamic monitoring in comparison to other green space indices using remote sensing images. The NDVI value varies from -1 to 1 . Higher the value of NDVI reflects high Near Infrared (NIR), which means dense greenery [24]. The values 0.2 and below represents the lack of green space, moderate values between 0.2 and 0.6 presents shrub and grassland, and values between 0.6 and 0.8 uncovers agricultural lands and parks on the consequential image.

In this study, normalized difference built-up index (NDBI) is used to estimate the built-up areas in Qorveh city [25, 31]. NDBI has a low value for vegetation cover. NDBI is formulated as follows:

$$
\text { NDBI = (SWIR 1- NIR) / (SWIR 1+NIR) }
$$

where SWIR 1 (Band 11) and NIR (Band 8) represent short wave near-infrared and near infrared reflectance, respectively. NDBI value lies between -1 to +1 . A negative value of NDBI represents water bodies while a higher value represents built-up areas. NDBI and NDVI images are used to model a multi-index image to present the spatial distribution of green spaces in the urban landscape. To calculate the urban green spaces and built-up areas, 1C-levelprocessed, cloudless Sentinel-2A images derived on August 8,2020 , were used to perform the analysis and evaluation.

UTM projection was used to project the Sentinel-2A images at $10-\mathrm{m}$ resolution using ArcGIS 10.6 software. The Sentinel-2 Multi-spectral Instrument (MSI) sensors supplies radiometrically and geometrically superior multi-spectral high spatial resolution images over the global surface, at high revisit time (5 days at the Equator) and a wide field of view covering $290 \mathrm{~km}$ with 13 bands.

Richer spatial and spectral content together with improved operational capabilities explain major advantages of Sentinel2 with respect to previous satellite derived products (e.g., Landsat series) [32].

\section{RESULTS}

It has been studied that NDVI analysis supplies one of the most precise green space measuring results. The resulting image of NDVI fundamentally uncovers the level of green space within the city boundary [25]. On Fig. 2, the color distinction between light and dark green signifies the level of green space arrangement within the study area. The areas showed by light green present a low green space, while areas colored by dark green represent the highest green space. It has been uncovered that Qorveh city center had a low green space cover with a NDVI range between -0.2 and 0.2 . In addition to the urban city center, the lowest NDVI values representing the lack of greenness were uncovered on the northern, southern, and eastern sides of the study area. As radiating out from an urban city center, the green space improved 
somehow by NDVI values between 0.1 and 0.20 , indicating the shrub and grassland presence. The moderate NDVI values between 0.2 and 0.6 were uncovered in the northern, northwestern, and western sides of the city, representing street trees, parks, and grasslands. The highest NDVI values between 0.6 and 0.8 were uncovered on the western side of the city, characterizing agricultural land cover. The range of green space cover values 0.1 and below represents the dearth of greenness.

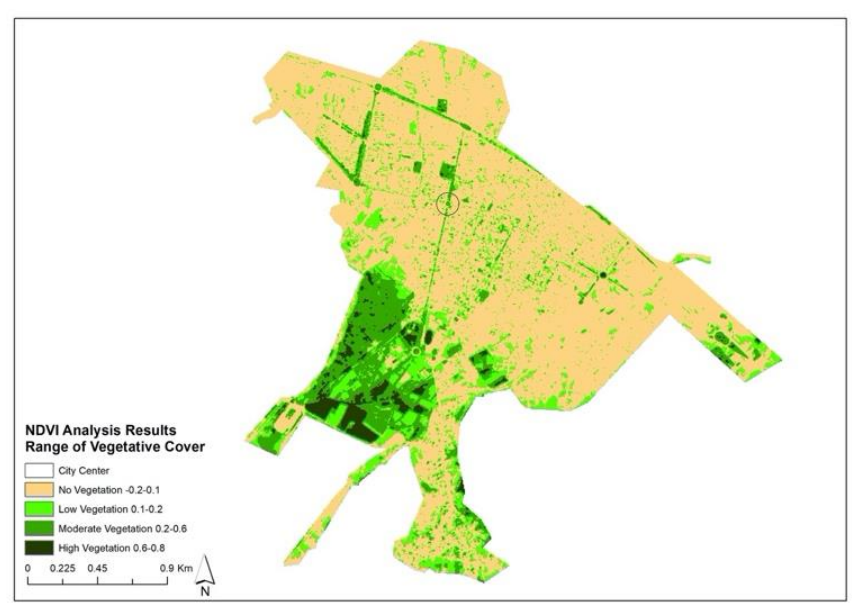

Fig. 2. NDVI Analysis Results.

NDBI analysis delivers one of the frequently applied builtup cover measuring consequences [25], and the resulting image of NDBI shows the level of urban built-up density within the city boundary. On Fig.3, the color variance between light and dark brown shows the level of built-up area arrangement within the study area. The areas represented by light brown present no built-up areas, while areas colored by dark brown show the highest built-up density. It has been uncovered that $39 \%\left(4.63 \mathrm{~km}^{2}\right)$ of the urban landscape is covered by buildings and $56 \%\left(6.79 \mathrm{~km}^{2}\right)$ is covered by barrens. The built-up environment is expanded in four directions from the city center, where green space limits to shrubs and grassland. On Fig. 3, built-up areas are expanded outwardly on the southwestern side of the city administrative boundary.

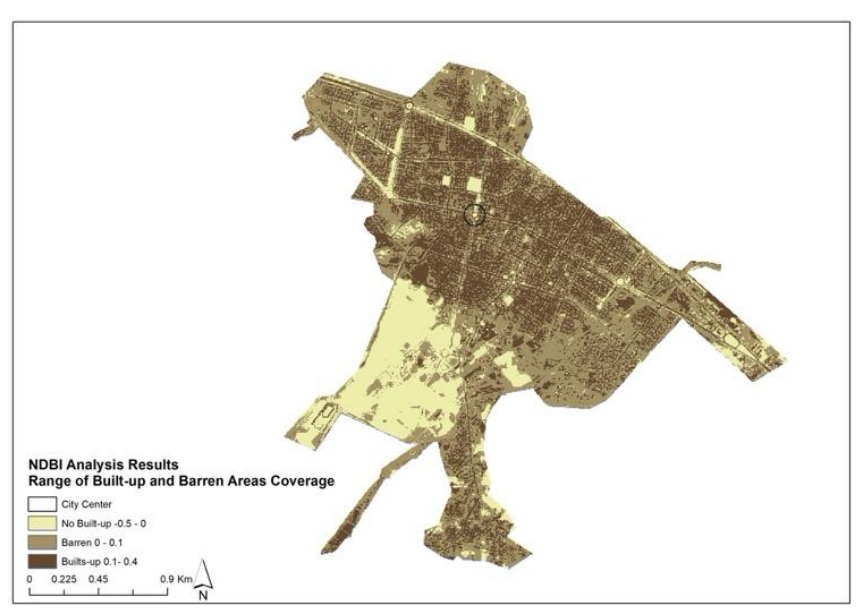

Fig. 3. NDBI Analysis Results.

On Fig. 4, the multi-index approach was constructed using combinations of NDVI and NBDI where each index represents green spaces and built-up areas, respectively. This multi-index image provides good discrimination between the two major categories- vegetation cover in green and the builtup areas in red. The highest multi-index value 0.44 presents dense built-up areas whereas the multi-index value 0.04 presents barren lands and -0.51 show green spaces. Small and large patches of barren lands are well distributed over the city. These lands can transform into green spaces and informal recreational areas.

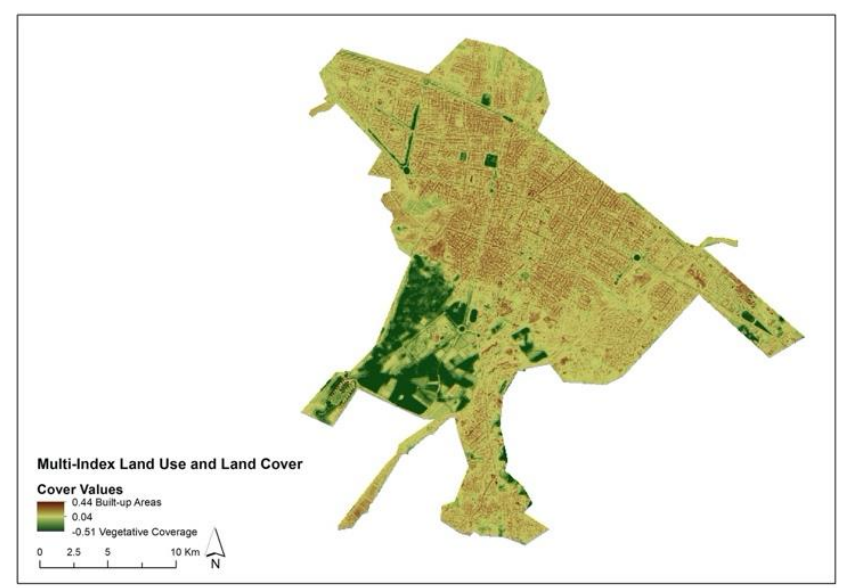

Fig. 4. Multi-Index Land Use and Land Cover.

The land use and land cover analysis results showed that the shrubs and grasslands are dominant green spaces and randomly cover urban landscape between $10 \mathrm{~m}^{2}$ and $25 \mathrm{~m}^{2}$ range per $100 \mathrm{~m}^{2}$ (Fig. 5a). Most importantly, these small green patches are not designed vegetated lands, including parks, community gardens, woods, and children's playgrounds. They are sparsely distributed shrubs and grasslands are degraded by human activities. Urban parks cover areas between $25 \mathrm{~m}^{2}$ and $53 \mathrm{~m}^{2}$ range per $100 \mathrm{~m}^{2}$ are located in northeastern side of the city center. Also, as radiating out from the city center, the green spaces division level considerably increased. Moreover, it has been found that the landscapes with greater NDVI values and more green space cover are allotted to the agricultural activities on the western side of the city. (Fig. 5a and Fig. 2). Equity in the spatial distribution of green spaces has not been adequate. On Fig. $5 b$, it has been found that the total built-up area value without green space is $9.28 \mathrm{~km}^{2}$ while the total built-up area with green space is limited to $2.12 \mathrm{~km}^{2}$.

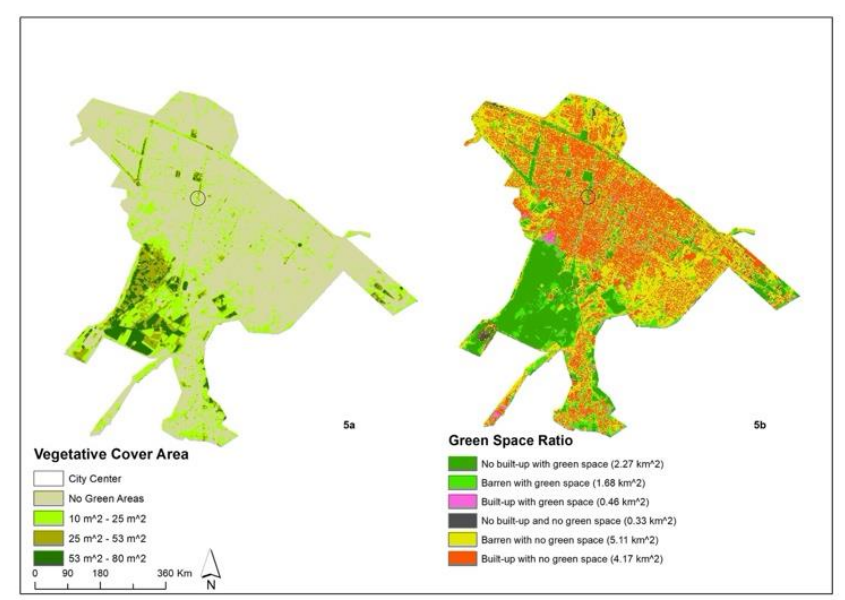

Fig.5. Vegetative Cover Area (Fig.5a) and Built-up Areas with Vegetative Cover (Fig. 5b). 


\section{Discussion}

This study investigates the spatial arrangement and green space distribution of Qorveh city by presenting the greatest existing level of green space cover within the city boundary and built-up area levels over the green space cover. In an effort to advance the broad variety of strength, geospatial analysis such as NDVI, NDBI, and Multi-index classification can define detailed information on how urbanization is associated with the spatial arrangement of the green spaces [25]. In Iran, the medium-sized cities have expanded in size providing services to surrounding large cities. While many small and medium-sized cities lack the infrastructure, facilities, and planned green spaces needed to promote residents' well-being [26]. Although industrialized nations may have benefitted from larger cities, the same is not true for the rapidly urbanizing areas of the developing world [27]. The relatively weak structure of urban policy forces challenges for the embracing of proper urban management strategies. Uncoordinated master planning strategies often deficiency information on the past, present, and future transformations to the urban and green space structure.

In the recent time, scholars link green space indices with high-resolution data of satellite images to quantify the significances of urban expansion [28]. In this study, NDVI and NDBI analysis outcomes revealed that the urban green space of Qorveh city is not planned efficiently. On both NDVI and Multi-index maps, the green space cover is assessed sparse in urban areas (Fig. 2, 4, 5b). Urban green spaces with low green space cover dispersed by small areas can cause negative environmental and social impacts. This unequal spreading of urban green space can therefore diminish the species productivity, and outward and inward urban growth may lead to habitat loss in the urban ecology [35]. Also, the Qorveh city is expanding onto nearby fertile agricultural lands as population increasing and dysfunctional urban center may contribute to the outward urban expansion and biodiversity loss [29]. Diminishing habitat and biodiversity loss and curbing degradation of ecosystem services also require medium-sized cities to integrate green space planning into their urban planning practices. In fact, the low green space distributed by large coverings reflect the same negative effects with the small coverings having the high green space cover [30]. NBDI results showed that small and large patches of barren lands distributed over the urban landscape. Land-use recycling is suggested to transform barren lands into green spaces and guard green spaces from densification and infilling [33].

Furthermore, the lowest NDVI values were found within the urban city center. One of the driving forces of the decline in green space is that urban greens might have minimized and become disintegrated by road and dysfunctional built-up construction. However, the impacts of roads and built-up construction could not be assessed in this study, due to insufficient data. By applying road and total built-up estimates, the drop of urban green spaces in Qorveh city can be broadly recognized.

Moreover, Qorveh city works as a secondary hub in reducing housing, pollution, transportation, and employment problems in the surrounding large cities, reducing regional inequalities, and mobilizing the rural economy by creating services, facilities, and markets for agricultural products in the area. It is therefore essential to incorporating green infrastructure goals and practices into urban landscape planning.

\section{CONCLUSION}

In recent years, planners have been pursuing consistent evidence and resolution factors to reduce green space loss and elucidate issues regarding insufficient green space cover data in built-up areas. Despite the complication of NDVI index interpretation and limitations in data acquisition of green space measurement, the results of this study can simplify understanding of negative results such as a decrease in green space spreading driven by infilling urban planning approach. While this is the first potential research that examined the relationship between built-up areas and urban green spaces in the city of Qorveh, the data is inhibited regarding how much of the urban green spaces have transformed over time.

Informing people about the significance of green spaces and their profits to social life is a solution for the negative impacts of urban development on urban green space. Also, cooperating with government associations to create a widespread database for green space measurement and green space fragmentation in urban city centers, and applying a maintenance plan for urban green areas' composition in the future are applicable strategies to control the green space loss. Therefore, the most available data is applied to direct any other future studies about the city of Qorveh. Through this, urban green spaces should be well-preserved and a simplified management plan should be employed by planners and decision-makers in the future.

\section{REFERENCES}

[1] Jennings V., Bamkole O. (2019), The Relationship between Social Cohesion and Urban Green Space: An Avenue for Health Promotion. International journal of environmental research and public health, 16(3), 452. https://doi.org/10.3390/ijerph16030452.

[2] Dennis M. and James P. (2016), User participation in urban green commons: Exploring the links between access, voluntarism, biodiversity and well-being. Urban For. Urban Green.5:22-31. doi: 10.1016/j.ufug.2015.11.009.

[3] Dinnie E., Brown K.M., Morris S. (2013), Reprint of "Community, cooperation and conflict: Negotiating the social well-being benefits of urban greenspace experiences" Landsc. Urban Plann.118:103-111. doi: 10.1016/j.landurbplan.

[4] MacKenzie A. and Gibbons, P. (2019) "Enhancing Biodiversity in Urban Green Space; An Exploration of the IAD Framework Applied to Ecologically Mature Trees." Urban Sci. 3, no. 4: 103.

[5] Braubach M., Egorov A., Mudu P., Wolf T., Ward Thompson C., Martuzzi M. (2017), Effects of Urban Green Space on Environmental Health, Equity and Resilience. In: Kabisch N., Korn H., Stadler J., Bonn A. (eds) Nature-Based Solutions to Climate Change Adaptation in Urban Areas. Theory and Practice of Urban Sustainability Transitions. Springer, Cham. https://doi.org/10.1007/978-3-31956091-5_11.

[6] Sandow E. and Lundholm E. (2020), Which families move out from metropolitan areas? Counterurban migration and professions in Sweden. European Urban and Regional Studies, 27(3), 276-289. https://doi.org/10.1177/0969776419893017.

[7] Dave S. (2010), High Urban Densities in Developing Countries: A Sustainable Solution? Built Environment (1978-), 36(1), 9-27. $\begin{array}{llll}\text { Retrieved November } & 30, & 2020, & \text { from }\end{array}$ http://www.jstor.org/stable/23289981.

[8] Chen W., Huang H., Dong J., Zhang, Y., Tian Y., Yang Z. (2018), Social functional mapping of urban green space using remote sensing and social sensing data, ISPRS Journal of Photogrammetry and Remote Sensing, Volume 146, Pages 436-452, ISSN 0924-2716, https://doi.org/10.1016/j.isprsjprs.2018.10.010. 
[9] World Health Organization (2017), Urban Green Spaces: a brief for action.

https://www.euro.who.int/__data/assets/pdf_file/0010/342289/Urban -Green-Spaces_EN_WHO_web3.pdf\%3Fua=1.

[10] Reynolds H., Brandt L., Widhalm M., Fei S., Fischer B., Hardiman B., Moxley D., Sandweiss E., Speer J., Dukes J (2018), "Maintaining Indiana's Urban Green Spaces: A Report from the Indiana Climate Change Impacts Assessment". Urban Green Spaces Reports. Paper 1. http://dx.doi.org/10.5703/1288284316653.

[11] Arghavani S., Malakooti H., Akbari A., Bidokhti, A.A. (2020), Numerical assessment of the urban green space scenarios on urban heat island and thermal comfort level in Tehran Metropolis, Journal of Cleaner Production, Volume 261, 2020, 121183, ISSN 0959-6526.

[12] [12] Sikuzani Y.U., Malaisse F., Cabala Kaleba S., Kalumba Mwanke A., Mwana Yamba A., Nkuku Khonde C., Bogaert J., Munyemba Kankumbi, F.(2019), Tree diversity and structure on green space of urban and peri-urban zones: The case of Lubumbashi City in the Democratic Republic of Congo, Urban Forestry \& Urban Greening, Volume 41, Pages 67-74,ISSN 16188667,https://doi.org/10.1016/j.ufug.2019.03.008.

[13] Wang A. and Chan E. (2019), Institutional factors affecting urban green space provision - from a local government revenue perspective, Journal of Environmental Planning and Management, 62:13, 23132329, DOI: 10.1080/09640568.2018.1541231.

[14] Xu G., Dong T., Brandful Cobbinah P., Jiao L., Sumari N.S., Chai B., Liu Y. (2019), Urban expansion and form changes across African cities with a global outlook: Spatiotemporal analysis of urban land densities, Journal of Cleaner Production, Volume 224, Pages 802-810, ISSN 0959-6526, https://doi.org/10.1016/j.jclepro.2019.03.276.

[15] Naikoo M.W., Rihan M., Ishtiaque M, Shahfahad (2020), Analyses of land use land cover (LULC) change and built-up expansion in the suburb of a metropolitan city: Spatio-temporal analysis of Delhi NCR using landsat datasets, Journal of Urban Management, Volume 9, Issue 3, Pages 347-359, ISSN 2226-5856, https://doi.org/10.1016/j.jum.2020.05.004.

[16] Alqurashi A.F. and Kumar (2019), An assessment of the impact of urbanization and land use changes in the fast-growing cities of Saudi Arabia, Geocarto International, 34:1, 78-97, DOI: 10.1080/10106049.2017.1367423.

[17] Gu C. (2019), Urbanization: Processes and driving forces. Sci. China Earth Sci. 62, 1351-1360. https://doi.org/10.1007/s11430-018-9359y.

[18] Gerten C, Fina S., Rusche K. (2019), The Sprawling Planet: Simplifying the Measurement of Global Urbanization Trends. Front. Environ. Sci. 7:140. doi: 10.3389/fenvs.2019.00140.

[19] Ramos-Santiago L. E., L. Villanueva-Cubero L. E. Santiago-Acevedo, Rodriguez-Melendez Y.N. (2014), Green area loss in San Juan's inner-ring suburban neighborhoods: a multidisciplinary approach to analyzing green/gray area dynamics. Ecology and Society 19(2): 4.

[20] Samiei A. and Sayafzadeh A. (2016), Analysis of the Worn-Out Tissues Characteristics and Providing of Intervention Pattern, Case Study: Eslamshahr City, Tehran. Current Urban Studies, 4, 267- 279.

[21] Zhu Z., Lang W., Tao X., Feng J., Liu K. (2019), Exploring the Quality of Urban Green Spaces Based on Urban Neighborhood Green Index - A Case Study of Guangzhou City. Sustainability,11, 5507.

[22] Agaie, T. (2012), the role of middle cities in development, case study Qorveh, urban development and sustainable architecture congress, Tehran, Iran [In Persian].

[23] Zarei P. and Ramesht M.H. (2011), Effects of Environmental Effects on physical development of Qorveh City, Congress, Mashad, Iran [In Persian].

[24] Siddique G., Roy A., Mandal M.H. et al. (2020), An assessment on the changing status of urban green space in Asansol city, West Bengal. GeoJournal. https://doi.org/10.1007/s10708-020-10312-2.

[25] Ettehadi Osgouei P., Kaya S., Sertel E., Alganci U. (2019), Separating Built-Up Areas from Bare Land in Mediterranean Cities Using Sentinel-2A Imagery. Remote Sens. 11, 345.

[26] Rondinelli D.A. (1983) Geographical Review, Vol. 73, No. 4, pp. 379395 Published by: Taylor \& Francis, Ltd. Stable URL: https://www.jstor.org/stable/214328.

[27] Frick S.A. and Rodríguez-Pose A. (2016), Average city size and economic growth, Cambridge Journal of Regions, Economy and Society, Volume 9, Issue 2, Pages 301-318.

[28] El Garouani A, Mulla D.J., El Garouan S.i, Knight J. (2017), Analysis of urban growth and sprawl from remote sensing data: Case of Fez, Morocco, International Journal of Sustainable Built Environment, Volume 6, Issue 1, Pages 160-169, ISSN 2212-6090, https://doi.org/10.1016/j.ijsbe.2017.02.003.
[29] Yagi H., Garrod G. (2018), The future of agriculture in the shrinking suburbs: The impact of real estate income and housing costs, Land Use Policy, Volume 76, Pages 812-822, ISSN 0264-8377, https://doi.org/10.1016/j.landusepol.2018.03.013.

[30] Li H., Chen W., He, W. (2015), Planning of Green Space Ecological Network in Urban Areas: An Example of Nanchang, China. International journal of environmental research and public health, 12(10), 12889-12904. https://doi.org/10.3390/ijerph121012889.

[31] Chunyang H., Peijun S., Dingyong X., Yuanyuan Z. (2010), Improving the normalized difference built-up index to map urban built-up areas using a semiautomatic segmentation approach, Remote Sensing Letters, 1:4, 213-221, DOI: 10.1080/01431161.2010.481681.

[32] Clerici N., Valbuena Calderón C.A, Posada J.M. (2017), Fusion of Sentinel-1A and Sentinel-2A data for land cover mapping: a case study in the lower Magdalena region, Colombia, Journal of Maps, 13:2, 718-726, DOI: 10.1080/17445647.2017.1372316.

[33] Vargas-Hernández J.G., Pallagst K., Zdunek-Wielgołaska J. (2018), Urban Green Spaces as a Component of an Ecosystem. In: Dhiman S., Marques J. (eds) Handbook of Engaged Sustainability. Springer, Cham. https://doi.org/10.1007/978-3-319-53121-2_49-1.

[34] Nor A.N.M., Corstanje R., Harris J.A., Brewer T. (2017), Impact of rapid urban expansion on green space structure, Ecological Indicators, $\begin{array}{lll}\text { Volume } & 81, \quad \text { Pages274-284, ISSN1470-160X }\end{array}$ https://doi.org/10.1016/j.ecolind.2017.05.031.

[35] Koivula M., Virta T., Kuitunen M., Vallius E. (2019), Effects of undergrowth removal and edge proximity on ground beetles and vascular plants in urban boreal forests, Journal of Urban Ecology, Volume 5, Issue 1, juz007, https://doi.org/10.1093/jue/juz007.

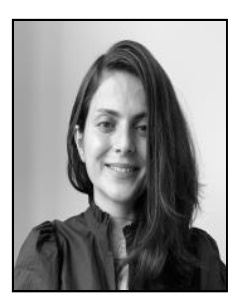

Aynaz Lotfata is an assistant professor of geography and urban planning at the Chicago State University, Illinois, where the core of her research centers on environmental justice, urban wellbeing, and application of geospatial methods in crossdisciplinary studies. Her interdisciplinary research initiatives demonstrate the integration of principles from various disciplines such as urban planning, geospatial sciences, and statistical modeling towards solving socio-environmental planning problems. With two doctoral degrees: one in City Planning, the other in Geosciences, and teaching Human and Natural Resource Conservation, and Urban and Regional Planning, she is committed to promoting socially and environmentally just urbanism. 